\section{Influence of Organic Acids from the Oral Biofilm on the Bond Strength of Self-Etch Adhesives to Dentin}

Cristiane Mariote Amaral, Danielly de Sá Correa, Luciana Meirelles Miragaya, Eduardo Moreira da Silva
Analytical Laboratory of Restorative Biomaterials, Dental School, UFF - Universidade Federal Fluminense, Niterói, RJ, Brazil

Correspondence: Profa. Cristiane Mariote Amaral, Rua Mário Santos Braga, $\mathrm{n}^{\circ} 30$ - Campus Valonguinho, Centro, 24020-140 Niterói, RJ, Brasil. Tel: +55-21-2629-9832. e-mail: camaral@vm.uff.br

\begin{abstract}
The aim of this study was to evaluate the microtensile bond strength of self-etch adhesive systems to dentin after storage in acids from oral biofilm. Three adhesive systems were used in the study: a two-step self-etch adhesive for use with a silorane-based resin composite (Filtek P90 adhesive system - P90), a two-step self-etch adhesive (Clearfil SE Bond - CSE) and a one-step self-etch adhesive (Adper Easy One - AEO). The bond strength of these products was evaluated by bonding resin composite (Filtek Z350 for CSE and AEO; and Filtek P90 for P90) to 90 bovine dentin tooth fragments, according to the manufacturer's instructions. After $24 \mathrm{~h}$ of water storage at $37^{\circ} \mathrm{C}$, the specimens were sectioned into beams $\left(1 \mathrm{~mm}^{2}\right)$ divided and stored in distilled water, lactic acid and propionic acid, for 7 and 30 days. After storage, the specimens were tested for microtensile bond strength. Data were analyzed by three-way ANOVA and Tukey's test $(\alpha=0.05)$. CSE presented the highest microtensile bond strength after storage in distilled water for 7 and 30 days. The microtensile bond strength of all adhesive systems was lower after storage in lactic acid and propionic acid than after water storage. Significant difference was not found between storage times.
\end{abstract}

Key Words: adhesion, self-etch adhesives, microtensile bond strength, organic acids.

\section{Introduction}

Although the success of dental adhesive restorations depends on several factors (1), a stable bond between resin composites and tooth substrates seems to be one of most important aspects in dental practice (2), as a poor adhesive interface can trigger various deleterious effects that may lead to loss of restoration in long-term observation (3).

Irrespective of the hybridization technique, using total-etch or self-etch adhesive systems, the hybrid layer obtained by the interaction between collagen fibers of the demineralized dentin and the resin monomers in dental adhesives, is the main coupling mechanism between tooth and restorative composites (2). Although extremely important for the success of adhesive restorations, the hybrid layer is known to be very susceptible to hydrolysis, which leads to weakening of the dentin-adhesive interface (4). This phenomenon occurs when using the etch-and-rinse strategy due to the persistence of unprotected collagen at the bottom of the hybrid layer, which can undergo a harmful enzymatic action $(2,5)$. Despite expectations that this condition would not occur with the self-etch adhesive system (6), a study has shown the existence of partially demineralized non-infiltrated zones under the hybrid layer obtained using these materials (6). This unexpected condition was found to be caused by the buffering effect of the tooth mineral content on the adhesive acidic monomers (5).
Despite the simplified clinical application of self-etch adhesives (6), the one-step self-etch systems have shown lower bond strengths (7) compared with other bonding techniques. This may occur due to the high concentration of solvents present in the adhesive system, which may impact negatively the polymerization reaction (8). As consequence, the permeability and the mechanical properties of the adhesive layer are compromised with these systems (8).

Restorative materials have various challenges in the oral environment, since they are subjected to several chemical and mechanical stresses. The most significant and detrimental chemical stressor is the hydrolytic degradation. Hydrolysis is a biomolecular reaction, the intensity and speed at which it occurs depends on the type of chemical bond, $\mathrm{pH}$, copolymer composition and water uptake (9). The $\mathrm{pH}$ affects degradation rates through catalysis and is more unlikely for hydrophilic resins (10) like the self-etch adhesives.

Most of the previous studies analyzing enamel/ dentin-adhesive degradation have used immersion media such as water (11) or artificial saliva $(12,13)$. The gingival margins of some restorations, including class $\mathrm{V}$ and II composite restorations and ceramic crowns, are close to areas constantly exposed to oral biofilm. Therefore, it seems important to analyze dentin-adhesive degradation resulting from the organic acids in oral biofilm (14), which has a high concentration of lactic acid (LA) and propionic 
acid (PA) (15). Earlier studies have shown that these acids have detrimental effects on surface degradation (16), solubility and sorption (17) of dimethacrylate resins and resin composites. It has also been observed that PA and LA may affect the bond strength of adhesive systems to human dentin (14). Therefore, the aim of this study was to evaluate the effect that organic acids from the oral biofilm have on the microtensile bond strength ( $\mu$ TBS) of self-etch adhesive systems to dentin, 7 days after placement and after 30 days of storage.

\section{Material and Methods}

\section{Tooth Preparation}

Ninety freshly extracted bovine incisors were stored in a $0.5 \%$ aqueous chloramine solution for 1 week and kept in distilled water until use in this study. The buccal surface of all teeth was polished with 100-grit SiC abrasive paper (DPU 10; Struers, Struer, Denmark) under constant irrigation until the exposure of dentin. In order to enlarge the area of exposed dentin ( $4 \times 6 \mathrm{~mm}), 400$-grit abrasive paper was then used. The teeth were viewed under a $20 x$ stereomicroscope (SZ40; Olympus, Tokyo, Japan) to confirm the complete absence of enamel. The dentin surface was then wet-polished with 600 -grit SiC abrasive paper for $20 \mathrm{~s}$ to standardize the smear layer. Afterwards, all teeth were cut with a diamond blade (KG Sorensen, São Paulo, $\mathrm{SP}$, Brazil) into $4 \times 6 \mathrm{~mm}$ fragments.

\section{Bonding Procedures}

The tooth fragments were randomly assigned to three groups $(n=30)$ according to the adhesive systems described in Table 1. The adhesive systems were applied strictly according to the manufacturers' instructions and composite blocks were fabricated on the dentin surfaces in four 1-mm increments. The composite Filtek P90 (3M-ESPE, St Paul, MN, USA) shade A3, was used for the P90 adhesive system group and Filtek Z350 (3M-ESPE) shade A3, was used for the other groups. Each increment of composite was light activated for $40 \mathrm{~s}$ at $510-540 \mathrm{~mW} / \mathrm{cm}^{2}$ using a quartz tungsten halogen unit (Optilux 501; Demetron/Kerr Corporation, Orange, CA, USA). The curing unit irradiance was monitored using a radiometer (Model 100; Demetron).

\section{Specimen Preparation}

After $24 \mathrm{~h}$ storage in distilled water at $37^{\circ} \mathrm{C}$, the teeth were serially sectioned in the " $x$ " and " $y$ " directions across the bonded interfaces (IsoMet 1000; Buehler, Lake Bluff, IL, USA) at $200 \mathrm{rpm}$ to obtain beams with a cross-sectional area of $1 \mathrm{~mm}^{2}$. The cross-sectional area at the adhesive interface of all beams was rounded up to the nearest 0.01 $\mathrm{mm}^{2}$ using a digital caliper (MPI/E-101; Mitutoyo, Tokyo, Japan), before microtensile bond strength testing.

\section{Storage Media and Microtensile Bond Strength ( $\mu$ TBS) Test}

The specimens from each adhesive system group were further divided into six subgroups ( $n=5$ teeth) according to medium and period of storage. The specimens were stored at $37{ }^{\circ} \mathrm{C}$ for 7 days or 30 days, in distilled water $(\mathrm{pH}=7)$, lactic acid $0.1 \mathrm{M}(\mathrm{pH}=2.6)$ or propionic acid $0.1 \mathrm{M}(\mathrm{pH}=2.9)$.

After the storage period, the beams were removed from the media, washed with distilled water and gently dried with absorbent paper. Next, the beams were fixed to a microtensile device (ODMT03d; Odeme Biotechnology, Joaçaba, SC, Brazil) with cyanoacrylate glue (Superbonder Gel; 3M, São Paulo, SP, Brazil) and loaded under tension

Table 1. Composition of the used self-etching adhesive systems

\begin{tabular}{|c|c|c|}
\hline $\begin{array}{l}\text { Adhesive } \\
\text { system }\end{array}$ & Composition & Manufacturer \\
\hline $\begin{array}{l}\text { P90 Adhesive } \\
\text { System }^{2} \text { (P90) }\end{array}$ & $\begin{array}{l}\text { Primer: HEMA, BIS-GMA, water, ethylalcohol, acid-methacryloxy-hexilesters, phosphoric } \\
\text { acid, silic treated with silicon, 1,6-hexanedioldimethacrylate, copolymer of acrylic } \\
\text { anditaconic acid,2-dimethylaminoethylmethacrylate, CQ, phosphine oxide } \\
\text { Adhesive: TEG-DMA, Dimethacrylate substitute, treated silica silanedimethacrylate, } \\
\text { methacryloxy-hexilesters, phosphoric acid, CQ, 1,6-hexanedioldimethacrylate }\end{array}$ & $\begin{array}{c}\text { 3M-ESPE, } \\
\text { St Paul, MN, USA }\end{array}$ \\
\hline $\begin{array}{l}\text { Adper Easy } \\
\text { One }^{1} \text { (AEO) }\end{array}$ & $\begin{array}{l}\text { HEMA, glycol bismethacrylate(1-methylethylidene) bis [4,1-fenilenooxi (2-hydroxy-3,1- } \\
\text { propanediyl)], water, ethylalcohol, phosphoric acid, 6-methacryloxy-hexilesters, silicon- } \\
\text { treated silica dimethacrylate,1,6-hexanediol, copolymer of acrylic anditaconic acid, } \\
\text { 2-dimethylaminoethylmethacrylate, CQ, diphenyl (2,4,6-trimetilbenzoil) - phosphine oxide }\end{array}$ & $\begin{array}{c}\text { 3M-ESPE, } \\
\text { St Paul, MN, USA }\end{array}$ \\
\hline $\begin{array}{l}\text { Clearfil SE } \\
\text { Bond (CSE) }\end{array}$ & $\begin{array}{c}\text { Primer: 10-MDP, HEMA, CQ, hydrophilic dimethacrylate, N,N-diethanol-p-toluidine, water. } \\
\text { Adhesive 10-MDP, HEMA, Bis-GMA, hydrophobic dimethacrylate, CQ, } \\
\text { N,N-diethanol-p-toluidine, silanated colloidal silica }\end{array}$ & $\begin{array}{l}\text { Kuraray } \\
\text { Medical -lnc., } \\
\text { Osaka, Japan }\end{array}$ \\
\hline
\end{tabular}

${ }^{1}$ Also known as Adper Easy Bond. ${ }^{2}$ Also known as Silorane System Adhesive and Filtek LS System Adhesive. 10-MDP: 10-methacryloyloxydecyl dihydrogen phosphate; HEMA: 2-hydroxyethyl methacrylate; CQ: camphorquinone; Bis-GMA: bisphenol A diglycidyl ether dimethacrylate; TEG-DMA: triethylene glycol dimethacrylate. 
using a universal testing machine (Emic DL 2000, São Paulo, $\mathrm{SP}, \mathrm{Brazil}$ ) at a crosshead speed of $1.0 \mathrm{~mm} / \mathrm{min}$ until failure occurred. The $\mu$ TBS value (MPa) was obtained dividing the load at failure $(\mathrm{N})$ by the cross-sectional area $\left(\mathrm{mm}^{2}\right)$ of the beams. The bond strength of each experimental unit (tooth) was the mean of bond strengths of the respective beams.

\section{Failure Mode}

Failure mode was analyzed under a stereomicroscope (SZ40; Olympus) at 40x magnification and classified as: adhesive (failure at the resin-dentin interface); cohesive on dentin (failure exclusively in dentin); cohesive on resin (failure exclusively in the composite); and mixed (failure at the resin-dentin interface that included cohesive failure of the neighboring substrates).

\section{Statistical Analysis}

The obtained data were analyzed using Statgraphics 5.1 Software (Manugistics, Rockville, MD, USA). Initially, the normal distribution of errors and the homogeneity of

Table 2. Means (pooled 7- and 30-day storages) and standard deviations of $\mu \mathrm{TBS}(\mathrm{MPa})$ of the adhesive systems to dentin

\begin{tabular}{lccc}
\hline \multirow{2}{*}{$\begin{array}{l}\text { Storage } \\
\text { medium }\end{array}$} & \multicolumn{3}{c}{ Adhesive system } \\
\cline { 2 - 4 } & $37.97(5.85) \mathrm{Aa}$ & $21.39(5.41) \mathrm{Ba}$ & $16.66(4.36) \mathrm{Ba}$ \\
Water & $24.86(2.81) \mathrm{Ab}$ & $13.48(4.48) \mathrm{Bb}$ & $9.09(3.40) \mathrm{Bb}$ \\
Lactic acid & $29.06(4.59) \mathrm{Ab}$ & $11.35(3.82) \mathrm{Bb}$ & $9.51(4.06) \mathrm{Bb}$ \\
\hline
\end{tabular}

Means followed by different letters (uppercase - row, lowercase - column) differ among them by Tukey's test at 0.05 confidence level. variances were checked using Shapiro-Wilk's and Levene's tests, respectively. Based on these preliminary analyses, the $\mu$ TBS data were analyzed by three-way ANOVA and Tukey's HSD test for multiple comparisons. The analyses were performed at a significance level of $\alpha=0.05$.

\section{Results}

Three-way ANOVA showed a statistical significance for the three independent factors: time $(p=0.03)$, immersion medium $(p=0.000)$ and adhesive system $(p=0.000)$, as well as for the interaction of adhesive system vs. immersion medium ( $p=0.0027$ ). On the other hand, no statistical significance ( $p>0.05)$ was observed for the interactions: time vs. immersion medium, time vs. adhesive system and time vs. immersion medium vs. adhesive system.

The results of $\mu$ TBS are in Table 2 as pooled average of $\mu$ TBS of the adhesive systems after 7 and 30 days storage. No significant difference was observed between 7 days or 30 days of storage. All adhesive systems presented lower $\mu \mathrm{TBS}$ after storage in propionic and lactic acid compared to water storage after 7 days or 30 days storage. CSE after water storage presented the highest $\mu \mathrm{TBS}$, followed by P90 and AEO. The lowest $\mu$ TBS was observed for P90 and AEO after immersion in propionic and lactic acid, after 7 days or 30 days of storage.

The failure mode analysis is shown in Figure 1 (7 days storage) and Figure 2 (30 days storage). CSE presented the highest percentage of cohesive failures in dentin after 7 days immersion in propionic and lactic acids. Meanwhile, a large amount of cohesive failures in resin was observed for the CSE specimens after immersion in water. Most failures

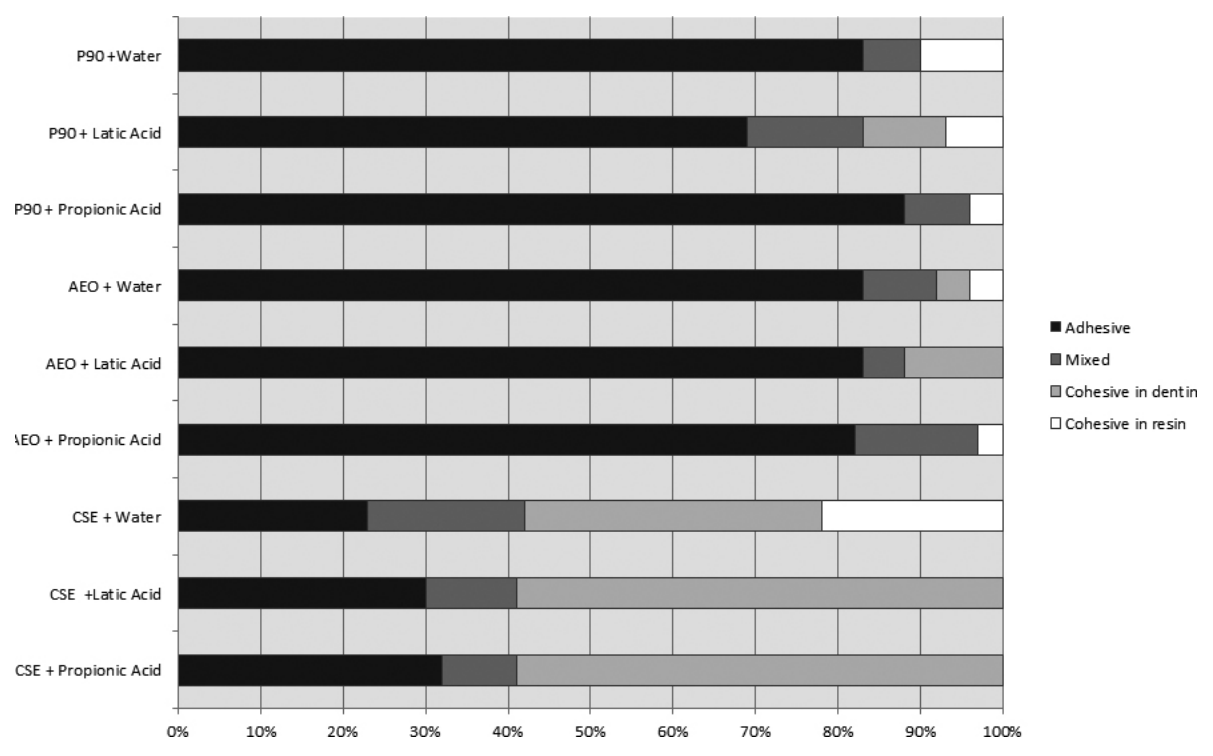

Figure 1. Failure mode (percentage) of adhesive systems after 7 days of storage. 
for the other adhesive systems were adhesive. For the 30day evaluation, in all groups adhesive failures prevailed, even in the CSE groups.

\section{Discussion}

Adhesive polymer structures are largely exposed to oral fluids and to organic acids in the oral biofilm. Several studies have shown that adhesive systems present hybrid layer degradation and a decrease in bond strength after aging in artificial saliva and water (11-13). The present study included lactic acid (LA) and propionic acid (PA) as immersion media before the bond strength evaluation to increase the knowledge regarding the degradation of adhesive systems in the oral environment. All adhesive systems were observed to have lower bond strength values after immersion in LA and PA when compared to water immersion. This occurred for both the 7 days and 30 days of storage, with no statistically significant differences between the two periods. This means that, irrespective of formulations, a common degradation ing mechanism was present for all the tested adhesive systems.

LA has been reported to increase absorption of the dentin-resin interface (18) and cause further damage to the bonded area (18) compared to immersion in water. Silva et al. (14) showed that the bond strength between dentin and some adhesives decreased after immersion for 7 days in LA and PA compared to immersion in artificial saliva. On the other hand, the results of Miranda et al. (9) indicate that LA and PA did not increase the sorption or solubility of the self-adhesive materials, while one bottle self-etch adhesive specimens presented more surface degradation and the highest sorption and solubility in that study.
It was inferred that the deleterious action of LA and PA on $\mu$ TBS occurs by two mechanisms. First, the $-\mathrm{OH}$ and $-\mathrm{COOH}$ functional groups from the molecules can establish a high level of hydrogen bonds with polar sites of methacrylate monomers present in the adhesive system, for example, -OH- in Bis-GMA, -0- in TEGDMA, and - $\mathrm{NH}$ - in UDMA, thus increasing the acid uptake by the polymeric phase of the hybrid layer (19). The findings of da Silva et al. (17), showing that LA diffused quicker in a resin composite than distilled water and artificial saliva, may reinforce this possibility. Second, the low pH of these entrapped acid molecules may have acted on the adhesive polymer by the catalysis of ester groups from the methacrylate monomers, thereby increasing degradation of the dentin-adhesive interface $(19,17,14)$. Moreover, the hydrolysis of these ester groups may produce alcohols and carboxylic molecules, which may accelerate adhesive polymer degradation by lowering the $\mathrm{pH}$ within the adhesive polymer (17).

Presence of HEMA in the adhesive systems may also have affected the water movement inside the adhesive polymer networks (20). Although HEMA is necessary as a co-solvent to improve the miscibility between the hydrophilic and hydrophobic monomers, it also acts as a wetting agent to help the monomer diffuse into the dentin collagen network, retaining water within the adhesive structure (21). This retained water can act as a plasticizer and decrease the adhesive mechanical properties with time (20). This change in mechanical properties may result over time in poor load transfer across the bonded interface, leading to catastrophic failure $(20,21)$. The exact concentration of HEMA contained in the adhesive systems in the current study was not disclosed by the manufacturers. The amount

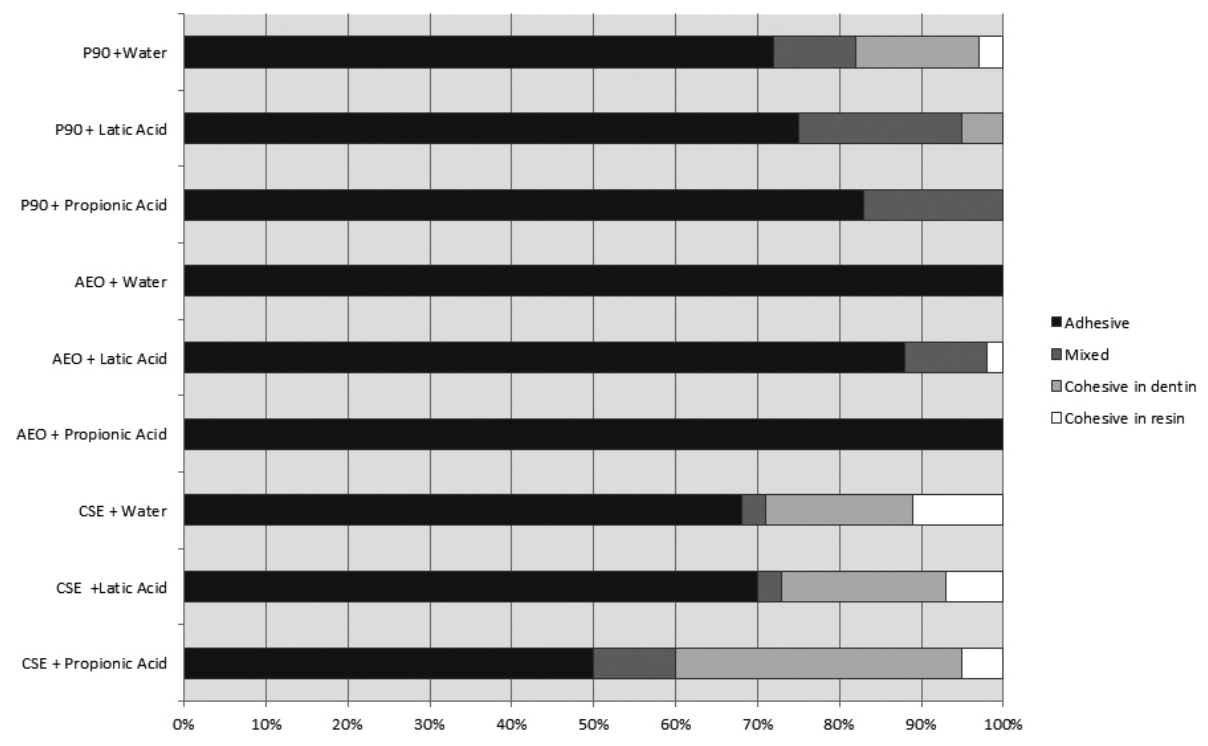

Figure 2. Failure mode (percentage) of adhesive systems after 30 days of storage. 
of this component can be seen as a decisive factor for the lowest bond strength presented by AEO after 30 days of immersion.

The adhesive systems P90 and AEO had lower bond strength compared to CSE after 7 days, regardless of immersion medium. However, there was no significant difference between P90 and AEO. On the other hand, after 30 days of immersion in water, AEO presented lower bond strength values compared to P90 and CSE. The worst performance presented by AEO can be directly related to its composition, which contains a complex mix of acidic and non-acidic monomers. Differences in the molecular weight and solubility parameters may have created differential monomer infiltration. These differences may have increased the monomer phase separation, which can create sites of acidic but non-polymerizable hydrolytic adhesive components, increasing the degradation at the dentinadhesive interface (5). Furthermore, the low performance of AEO may be related to the high permeability of the bond interface created by one-bottle self-etch adhesives, thereby contributing to its hydrolytic instability (14). This degradation may occur due to water absorption that can interfere with Van der Waals forces (9).

The bond strength of self-etch adhesive systems to dentin has been considered acceptable, but it is materialdependent (22). CSE presented the best results, which is not surprising, as this result has previously been published $(11,22)$. The probable reason for that performance is the presence of 10-MDP. Due to its long carbonyl chain, this functional methacrylate monomer is hydrolytically stable, which can contribute to its higher bond stability (23). Additionally, the high chemical bonding potential of 10MDP to hydroxyapatite (23) may also provide an explanation for the better results of CSE, since chelates are formed between the $-\mathrm{COOH}$ groups of $10-\mathrm{MDP}$ and the $++\mathrm{Ca}$ ions of the residual hydroxyapatite between collagen fibers (11).

It is known that hybrid layer degradation is related to a decreased effectiveness of the chemical bonds after water storage. Water can infiltrate into and decrease the mechanical properties of the polymer matrix by causing swelling and reducing the frictional forces between the polymer chains in a process known as "plasticizing" (24). There is also a decrease of the bonding strength in the presence of water as consequence of the hydrolytic degradation of collagen (13). It is likely that 30 days immersion in water was insufficient to cause degradation in the current study, which explains the absence of a statistically significant difference between the two storage periods.

CSE presented a higher percentage of cohesive failures in dentin compared to the other adhesive systems after 7 days of immersion. However, after 30 days of immersion, an increase in the number of adhesive failures was observed for all adhesive systems, irrespective of the immersion media. It is speculated that immersion for a longer time can lead to weakening of the adhesive layer, which could lead to an increase in adhesive failures at the dentin-adhesive interfaces. Chiaraputt et al. (25) also found a large number of cohesive failures during the immediate evaluation of CSE specimens, while a larger number of adhesive failures was observed after increasing the storage time (3 months). Those authors attributed the findings to the deleterious effect of water molecules at the bond interface of micro specimens.

In conclusion, the results of this current study showed that acids in the oral biofilm may negatively affect the bond strength of self-etch adhesive systems to dentin. Moreover, the two-step self-etch adhesive system (CSE) presented higher bond strengths to dentin, followed by a two-step adhesive system for use with silorane based-composites (P90) and a one-step self-etching adhesive system (AEO), in all immersion media.

\section{Resumo}

0 objetivo deste trabalho foi avaliar a resistência de união de sistemas adesivos autocondicionantes após estocagem em ácidos presentes no biofilme oral. Foram utilizados três sistemas adesivos: um autocondicionante de dois frascos indicado para uso com a resina composta à base de silorano (P90 System Adhesive- P90), um autocondicionante de dois frascos (Clearfil SE Bond - CSE) e um autocondicionante de frasco único (AdperEasyOne - AEO). Para avaliação da resistência de união à dentina, 90 fragmentos de dentes bovinos foram restaurados de acordo com as recomendações dos fabricantes. Após a confecção de blocos de resina composta (Filtek Z350 para os sistemas adesivos AEO e CSE; Filtek P90 para o sistema adesivo P90) e estocagem em água destilada por 24 $\mathrm{h}$ a $37^{\circ} \mathrm{C}$, os fragmentos foram seccionados para a obtenção de palitos $\left(1 \mathrm{~mm}^{2}\right)$ que foram divididos e estocados nos três diferentes meios de imersão (água destilada, ácido lático e ácido propiônico) por periodos de 7 dias e 30 dias $(n=5)$. Em seguida, foi realizado o ensaio de resistência à microtração. Os dados foram submetidos à Análise de Variância (3 fatores) e ao Teste de Tukey $(\alpha=0,05)$. 0 sistema adesivo CSE apresentou maior resistência de união após imersão em água por 7 ou 30 dias. A resistência de união de todos os sistemas adesivos foi menor após imersão em ácido lático e propiônico do que após imersão em água. Não foi observada diferença significativa entre os tempos de imersão.

\section{References}

1. Schneider $H_{1}$ Busch I, Busch $M$, Jentsch $H$, Hafer M. Effect of operatorspecific handling on tooth-composite interface and microleakage formation. Oper Dent 2009;34:200-210.

2. Hashimoto $M$, Ohno $H$, Kaga $M$, Endo $K$, Sano $H$, Oguchi $H$. In vivo degradation of resin-dentin bonds in humans over 1 to 3 years. J Dent Res 2000;79:1385-1391

3. Kubo S, Yokota H, Yokota H, Hayashi Y. Three-year clinical evaluation of a flowable and a hybrid resin composite in non-carious cervical lesions. J Dent 2009;38:191-200.

4. Armstrong SR, Vargas MA, Chung I, Pashley DH, Campbell JA, Laffoon $\mathrm{JE}_{\text {, et }}$ al.. Resin-dentin interfacial ultrastructure and microtensile dentin bond strength after five-year water storage. Oper Dent 2004;29:705-712.

5. Carvalho RM, Chersoni S, Frankenberger R, Pashley DH, Prati C, Tay FR. A challenge to the conventional wisdom that simultaneous etching and resin infiltration always occurs in self-etch adhesives. Biomater 
2005;26:1035-1042

6. Van Meerbeek B, De Munck J, Yoshida Y, Inoue S, Vargas M, Vijay P, et al.. Buonocore memorial lecture. Adhesion to enamel and dentin: current status and future challenges. Oper Dent 2003;28:215-235.

7. Amaral RC, Stanislawczuk R, Zander-Grande C, Gagler D, Reis A, Loguercio AD. Bond strength and quality of the hybrid layer of onestep self-etch adhesives applied with agitation on dentin. Oper Dent 2010;35:211-219.

8. Cadenaro M, Breschi L, Antoniolli F, Navarra CO, Mazzoni A, Tay FR, et al.. Degree of conversion of resin blends in relation to ethanol content and hydrophilicity. Dent Mater 2008;24:1194-1200.

9. Miranda MESNG, de Oliveira Scudine KG, Noronha Filho JD, da Silva EM, Amaral CM. Sorption and solubility of self-etching adhesives immersed in organic acids present in oral biofilm. J Adhes Dent. 2014;16:115-122.

10. Cilli R, Pereira JC, Prakki A. Properties of dental resins submitted to $\mathrm{pH}$ catalysed hydrolysis. J Dent. 2012;40:1144-1150.

11. Abdalla Al, Feilzer AJ. Four-year water degradation of a total-etch and two self-etching adhesives bonded to dentin. J Dent 2008;36:611-617.

12. Sadek FT, Castellan CS, Braga RR, Mai S, Tjaderhane L, Pashley DH, et al.. One-year stability of resin-dentin bonds created with a hydrophobic ethanol-wet bonding technique. Dent Mater 2010;26:380-386.

13. Breschi $L$, Mazzoni A, Nato F, Carrilho M, Visintini $E$, Tjaderhane $L$, et al.. Chlorhexidine stabilizes the adhesive interface: A 2-year in vitro study. Dent Mater 2010;26:320-325.

14. Silva EM, Almeida GS, Poskus LT, Guimarães JG. Influence of organic acids present in the oral biofilm on the microtensile bond strength of adhesive systems to human dentin. J Biomed Mater Res B Appl Biomater 2012;100:735-741.

15. Borgstrom MK, Edwardsson S, Sullivan A, Svensater G. Dental plaque mass and acid production activity of the microbiota on teeth. Eur J Oral Sci 2000;108:412-417.

16. Bagheri R, Tyas MJ, Burrow MF. Subsurface degradation of resin-based composites. Dent Mater 2007;23:944-951.
17. da Silva EM, Goncalves L, Guimaraes JG, Poskus LT, Fellows CE. The diffusion kinetics of a nanofilled and a midifilled resin composite immersed in distilled water, artificial saliva, and lactic acid. Clin Oral Investig 2011;15:393-401.

18. Prati C, Chersoni S, Acquaviva GL, Breschi L, Suppa P, Tay FR, et al.. Permeability of marginal hybrid layers in composite restorations. Clin Oral Investig 2005;9:1-7.

19. Fukuoka A, Koshiro $K$, Inoue $S$, Yoshida $Y$, Tanaka $T$, Ikeda $T$, et al.. Hydrolytic stability of one-step self-etching adhesives bonded to dentin. J Adhes Dent 2011;13:243-248.

20. Hosaka K, Nakajima M, Takahashi M, Itoh S, Ikeda M, Tagami J, et al.. Relationship between mechanical properties of one-step self-etch adhesives and water sorption. Dent Mater 2010;26:360-367.

21. Van Landuyt KL, De Munck J, Snauwaert J, Coutinho E, Poitevin A, Yoshida $Y$, et al.. Monomer-solvent phase separation in one-step selfetch adhesives. J Dent Res 2005;84:183-188.

22. Osorio R, Pisani-Proenca J, Erhardt MCG, Osorio E, Aguilera FS, Tay FR, et al.. Resistance of ten contemporary adhesives to resin-dentine bond degradation. J Dent 2008;36:163-169.

23. Yoshida $Y$, Nagakane $K$, Fukuda R, Nakayama Y, Okazaki M, Shintani $\mathrm{H}$, et al.. Comparative study on adhesive performance of functional monomers. J Dent Res 2004;83:454-458.

24. Ferracane $\mathrm{JL}$, Berge $\mathrm{HX}_{1}$ Condon JR. In vitro aging of dental composites in water - effect of degree of conversion, filler volume, and filler/ matrix coupling. J Biomed Mater Res 1998;42:465-472.

25. Chiaraputt $S$, Roongrujimek $P$, Sattabanasuk $V$, Panich N, Harnirattisai C, Senawongse P. Biodegradation of all-in-one self-etch adhesive systems at the resin-dentin interface. Dent Mater J 2011;30:814-826.

Received October 8, 2014

Accepted May 13, 2015 